\title{
STUDY THE RESPONSE SURFACE OF ABS COMPOSITE OF PROCESS PARAMETERS FABRICATED USING 3D PRINTING TECHNIQUE
}

\author{
K.G. Jaya Christiyan ${ }^{1} *$, U. Chandrasekhar ${ }^{2}$, K. Venkateswarlu ${ }^{3}$ \\ ${ }^{I}$ M S Ramaiah Institute of Technology, Bangalore -560054. \\ ${ }^{2}$ Vel Tech Dr. RR \& Dr. SR Technical University, Chennai-600062. \\ ${ }^{3}$ CSIR-National Aerospace Laboratories, Bangalore-560017. \\ *13ayachristiyan@gmail.com : +919008671957
}

\begin{abstract}
Rapid prototyping $(R P)$ technologies have been emerged as a fabrication method to obtain engineering components within a short span of time. In this method components weremodeledusing three dimensionalcomputer aided designand fabricated using fused deposition modeling technique, so called as desktop 3 D printer. In this present investigation, ABS + hydrous magnesium silicate compositewas considered as material for fabricating components, andmechanical properties of ABS compositewere evaluated. For the fabrication and test of samples ASTM standardswas followed.Samples were prepared with different layer thicknessand printing speed were prepared. Based on the experimental results, it is suggested that samples with low printing speed, and low layer thickness has resulted maximum tensile and flexural strength. This investigation not only provides a complex dependency of mechanical properties on manufacturing process parameters, but develops a statistical significant influence of printing speed and layer thickness. It is concluded that mechanical properties are greatly influenced by the printing speed and the layer thickness, but printing speed is more influence than the layer thickness.
\end{abstract}

Keywords:ABS Composite; FDM; ANOVA; 3D Printing;Mechanical Properties.

\section{INTRODUCTION}

RP technique is extensively used to fabricate scale models of physical parts or assemblies using three-dimensional computer aided design (CAD) data at a faster rate. FDM is a technique in RP that is based on surface chemistry, thermal energy, and layer manufacturing technology. In this process, filaments of heated thermoplastic are extruded from a tip that moves in the $\mathrm{x}-\mathrm{y}$ plane. The CAD data is fed to the 3D printingsoftware and generate NC codes, the NC codes are given input to $3 \mathrm{D}$ printing machine.That allow designers to quickly create tangible prototypes of designs, rather than just two-dimensional drawing. The material extrude from the nozzle and deposited on the table based on the NC code generated by the software, once one layer is completed the table moves down of an layerthickness and the process will continues is called additive manufacturing (AM) process [1], commonly known as FDM. As a result, much of the research is focused on transforming this technology towards manufacturing production grade material and end use products [2]. Existing commercial AM machines are currently being modified to an extent to improve their accuracy and capabilities. However, high cost, material restriction, and difficulty in studying process parameters are an issue. But in this context, the present work is focused on the study and optimization of a novel open-source and lowcost 3D printing machine is used, for the fabrication of samples. Several manufacturing process parameters are there in that layer thickness and printing speed are considered for the present study.
The controlled extrusion head deposits very thin beads of material onto the build platform to form the first layer [3-6]. The platform is maintained at a low temperature, so that the thermoplastic is quickly hardens. After the platform is lowered by the specified distance (i.e., layer thickness), the extrusion head deposits a second layer upon the first. The process is continued to form the desired prototype of specified dimensions [7]. Supports are built along the way, fastened to the part either with a second weaker material or with a perforated junction.

Said et. al. [6] have studiedfive different raster orientation causes alignment of polymer molecules along with the direction of deposition during evaluation processof the tensile and flexural samples. Since semi-molten filament is extruded from nozzle tip and solidified in a chamber maintained at certain temperature, change of phase is likely to occur. As a result, volumetric shrinkage takes place resulting a weak interlayer bonding and high porosity. Ahn et. al. [8] have reported that process parameters such as air gap and raster orientation significantly affect the tensile strength of FDM fabricated part as compared to other parameters suchas raster width, model temperature and colors through experimental design and analysis. In addition, built parts exhibit anisotropic properties depending on build orientation as far as tensile and flexural strength is concerned. Khan et. al. [9] have alsoproposedexperimentally and statistical approach to design optimization of ABS part fabricated through FDM technique that the layer thickness, 
raster angle and air gap are the three main influence process parameters that effects the elastic performance of the ABS prototype parts. Lee et. al. [10] have studiedtwo different manufacturing method like 3D printer and nano composite deposition (NCDS). In 3D printing five various process parameter were considered such as raster orientation, air gap, bead width, color, and model temperature for FDM method. Sampleswas measured compressive strengths, and most of them showed anisotropic compressive properties.Experimental results show that compressive strength has more by $11.6 \%$ for axial sample as compared to transverse sample. It has been notices that the deformation was more in bottom layers than the upper layers, and high stacking section lengths are responsible for large deformations. If chamber temperature was increased, deformation gradually decreased and became zero when chamber temperature equals glass transition temperature of material. Hence, it was proposed that material used for part fabrication must have lower glass transition temperature and linear shrinkage rate.In this paper, tensile strength properties of $\mathrm{ABS}+$ hydrous magnesium silicate composite material made by desktop 3D printer process with different build parameters such as layer thickness and printing speed are discussed.

\section{EXPERIMENTAL DETAILS}

The initial goal was to manufacture the samples withvarious process parameters. The samples were maintain fixed and varying parameter (table 2 and 1). The varying manufacturing parameters are different layer thickness $(0.2$ $\mathrm{mm}, 0.25 \mathrm{~mm}$ and $0.3 \mathrm{~mm}$ ) and with different printing speeds $(30 \mathrm{~mm} / \mathrm{s} .40 \mathrm{~mm} / \mathrm{s}$ and $50 \mathrm{~mm} / \mathrm{s})$. For all the sample are preparedwith fixed parameter, like nozzle diameter $(0.6$ $\mathrm{mm})$, extruder temperature $\left(\sim 240^{\circ} \mathrm{C}\right)$ and the built platform temperature $\left(70^{\circ} \mathrm{C}\right)$. Based on the statistical modeling tool ANOVA,for this process condition 13 different combination of samples are given. All combination were subjected to tensile and flexural tests condition. For the slicing of data and feeding the process parameters slice $3 \mathrm{r}$ software was used. The test samples were modeled and manufactured using ASTM standards.

Table: 1 Various process conditions for specimen preparation

\begin{tabular}{llll}
\hline $\begin{array}{l}\text { Sample } \\
\text { parameter }\end{array}$ & Sample 1 & Sample 2 & Sample 3 \\
\hline $\begin{array}{l}\text { Layer thickness, } \\
\mathrm{mm}\end{array}$ & $\mathrm{L} 1=0.2$ & $\mathrm{~L} 2=0.25$ & $\mathrm{~L} 3=0.3$ \\
$\begin{array}{l}\text { Printing Speed, } \\
\mathrm{mm} / \mathrm{s}\end{array}$ & $\mathrm{S} 1=30$ & $\mathrm{~S} 2=40$ & $\mathrm{~S} 3=50$ \\
$\begin{array}{l}\text { Nozzle } \\
\text { diameter, } \mathrm{mm}\end{array}$ & $\mathrm{N} 1=0.4$ & $\mathrm{~N} 1=0.5$ & $\mathrm{~N} 1=0.6$ \\
\hline
\end{tabular}

Table : 2Fixed Factors

\begin{tabular}{lll}
\hline Factor & Unit & Values \\
\hline Part Fill style & degree & $45 /-45$ \\
Nozzle Temperature & ${ }^{\circ} \mathrm{C}$ & 240 \\
Bed temperature & ${ }^{\circ} \mathrm{C}$ & 70 \\
Infill & $\%$ & 70 \\
\hline
\end{tabular}

For testing the samples an Intron-universal testing machine with $10 \mathrm{KN}$ load cell was used. Different fixtures were used based on ASTM standard, for testing the samples. The machine was maintained a cross head speed of $1 \mathrm{~mm} / \mathrm{min}$ for the tensile and the flexural samples. The tensile test was stopped when the specimen reaches $2.5 \%$ elongation or the specimen breaks. A 3 point bendmethod was followed for the flexural strength. Since the physical properties of many materials (especially thermoplastics) can vary depending on ambient temperatures, it is desired to test samples at temperatures that simulate the intended end user environment [11].

\section{RESPONSE SURFACE METHODOLOGY} AND EXPERIMENTAL DESIGN

RSM is a method of finding the option of an independent manufacturing constraints in the magnitudes form as:

$y=f\left(x_{1}, x_{2}, x_{3}, \ldots \ldots x_{n}\right) \pm \varepsilon$

Analysis of Variance (ANOVA) [12]is performed to foresee the proposed model by utilizing the second request relapse examination are ascertained and organized in Table 3. ANOVA gives a thought regarding the quadratic model for conceiving the flexural quality of tests with relapse esteem $\mathrm{p}$ under 0.05 are critical. For this investigation $2^{2}$ factorial experimentation method was follows, with total thirteen experiment. Table 3 provide the detail of sample preparation method using ANOVA.

\section{RESULTS AND DISCUSSION}

\subsection{Tensile test}

Tensile strength is determined for RP models prepared from a $0.6 \mathrm{~mm}$ diameter nozzle with variation in printingspeed and layer thickness. It is found that the tensile stressis decreased with increase in layer thickness as well tensile stressis decreased with increase in printing speed. However, this effect is less as the layer thicknessis increased. Therefore, the layer thickness played a significant role in tensile properties of $\mathrm{ABS}+$ hydrous magnesium silicate compositematerial printed with $0.6 \mathrm{~mm}$ diameter nozzle and $60 \%$ fill density.

Table 4 provides the fit summary of the quadratic model before elimination. It is statistically significant for analysis of tensile stress. This results quadratic model for tensile stress in the form of ANOVA were given in the Table 4: The $\mathrm{R}^{2}$ value was $99.15 \%$. This clearly indicates the regression graph provides an admirable description to the correlation between the tensile stress and the independent factors. The $\mathrm{p}$-value of the model is lower than 0.05 or $95 \%$ confidence indicated that the model is considered as statistically significant. From the ANOVA technique, it is calculated that the value of $F$ ratio of the proposed model doesn't exceeded the standard value. The effect of the factor for $F$ value is high, that indicate the facture is more influence the response process. 
Table:3ANOVA table for ABS composites

\begin{tabular}{rrrrrr}
\hline \multirow{2}{*}{ Run } & Std & $\begin{array}{r}\text { Factor 1. } \\
\text { Layer thickness }\end{array}$ & Factor 2. Printing Speed & R1: Tensile stress & R2: Flexural Strength \\
\hline 1 & 1 & 0.2 & 30 & 28.5 & 48.59 \\
2 & 2 & 0.3 & 30 & 25.5 & 37.29 \\
3 & 3 & 0.2 & 50 & 25 & 36.16 \\
4 & 11 & 0.25 & 40 & 24 & 35.03 \\
5 & 5 & 0.2 & 40 & 27 & 41.81 \\
6 & 8 & 0.25 & 50 & 21 & 33.9 \\
7 & 10 & 0.25 & 40 & 24 & 35.03 \\
8 & 6 & 0.3 & 40 & 24.5 & 35.03 \\
9 & 12 & 0.25 & 40 & 24 & 35.03 \\
10 & 9 & 0.25 & 40 & 24 & 35.03 \\
11 & 4 & 0.3 & 50 & 18 & 24.86 \\
12 & 13 & 0.25 & 40 & 24 & 35.03 \\
13 & 7 & 0.25 & 30 & 26 & 38.42 \\
\hline
\end{tabular}

Table: 4ANOVA -Response Surface Reduced Quartic model for Tensile stress without elimination

\begin{tabular}{lllllll}
\hline Source & Sum of Squares & df & Mean Square & F Value & P-Value & Effect \\
\hline Model & 80.12 & 7 & 11.45 & 82.98 & $<0.0001$ & significant \\
A-Layer Thickness & 3.12 & 1 & 3.12 & 22.66 & 0.0051 & Significant \\
B-Printing Speed & 12.50 & 1 & 12.50 & 90.62 & 0.0002 & significant \\
$\mathrm{AB}$ & 4.00 & 1 & 4.00 & 29.00 & 0.0030 & significant \\
$\mathrm{A}^{\wedge} 2$ & 4.44 & 1 & 4.44 & 32.16 & 0.0024 & significant \\
$\mathrm{B}^{\wedge} 2$ & 2.67 & 1 & 2.67 & 19.34 & 0.0070 & significant \\
$\mathrm{A}^{\wedge} 2 \mathrm{~B}$ & 0.083 & 1 & 0.083 & 0.60 & 0.4721 & In-significant \\
$\mathrm{AB}^{\wedge} 2$ & 2.08 & 1 & 2.08 & 15.10 & 0.0116 & significant \\
Residual & 0.69 & 5 & 0.14 & & & \\
Lack of Fit & 0.69 & 1 & 0.69 & & & \\
Pure Error & 0.000 & 4 & 0.000 & & & \\
Cor Total & 80.81 & 12 & & & & \\
\hline
\end{tabular}

$\mathrm{R}^{2}=0.9915$, adj. $\mathrm{R}^{2}=0.9795$

Coded factor equation

Tensile $\quad 24.14-1.25 \times \mathrm{A}-2.5 \times \mathrm{B}-\mathrm{AB}+$

stress $=\quad 1.27 \times \mathrm{A}^{\wedge} 2-0.98 \times \mathrm{B}^{\wedge} 2-0.25 \mathrm{x}$ $\mathrm{A}^{\wedge} 2 \mathrm{~B}-1.25 \times \mathrm{AB}^{\wedge} 2$

The transformed value of the coded factors (A and B) with the actual factors, hence the Eq. 2 can be written as:

Tensile $\quad 24.14-1.25$ x Layer Thickness -

stress $=\quad 2.5 \times$ Printing Speed - Layer

Table:5 ANOVA -Response Surface Reduced Quartic model for Tensile stress after elimination

\begin{tabular}{|c|c|c|c|c|c|c|c|}
\hline $\begin{array}{l}\text { Sourc } \\
\mathrm{e}\end{array}$ & $\begin{array}{r}\text { Sum } \\
\text { of } \\
\text { Squa } \\
\text { res }\end{array}$ & $\begin{array}{l}\mathrm{d} \\
\mathrm{f}\end{array}$ & $\begin{array}{r}\text { Mea } \\
n \\
\text { Squ } \\
\text { are }\end{array}$ & $\begin{array}{r}\text { F } \\
\text { Val } \\
\text { ue }\end{array}$ & $\begin{array}{r}\text { P- } \\
\text { Val } \\
\text { ue }\end{array}$ & Effect & $\begin{array}{r}\% \\
\text { contrib } \\
\text { ution }\end{array}$ \\
\hline Model & $\begin{array}{r}80.0 \\
3\end{array}$ & 6 & $\begin{array}{r}13.3 \\
4\end{array}$ & $\begin{array}{r}103 . \\
54\end{array}$ & $\begin{array}{r}<< \\
0.00 \\
01\end{array}$ & $\begin{array}{l}\text { signifi } \\
\text { cant }\end{array}$ & 99.04 \\
\hline $\begin{array}{l}\text { A- } \\
\text { Layer } \\
\text { Thick } \\
\text { ness }\end{array}$ & 3.13 & 1 & 3.13 & $\begin{array}{r}24.2 \\
6\end{array}$ & $\begin{array}{r}0.00 \\
26\end{array}$ & $\begin{array}{l}\text { signifi } \\
\text { cant }\end{array}$ & \\
\hline $\begin{array}{l}\text { B- } \\
\text { Printi } \\
\text { ng } \\
\text { Speed }\end{array}$ & $\begin{array}{r}42.6 \\
7\end{array}$ & 1 & $\begin{array}{r}42.6 \\
7\end{array}$ & $\begin{array}{r}331 . \\
18\end{array}$ & $\begin{array}{r}< \\
0.00 \\
01\end{array}$ & $\begin{array}{l}\text { signifi } \\
\text { cant }\end{array}$ & 52.8 \\
\hline
\end{tabular}

Thickness x Printing Speed +1.27

x Layer thickness`2 -0.98 x

Printing Speed ${ }^{\wedge} 2-0.25$ x Layer

Thickness 2 x Printing Speed -

1.25 x Layer thickness x Printing Speed $^{\wedge} 2$ 
Table 5 shows the ANOVA table of quadratic model after the backward elimination. The result of the reduced model shows that the model is significant with a $\mathrm{R}^{2}$ value as $99.04 \%$ and the adjutant $\mathrm{R}^{2}$ value as $98.09 \%$. The effect of the significant $\mathrm{F}$ values and the factor $\mathrm{A}$ is Layer thickness, factor B Printing speed, combination first order term factor of $\mathrm{AB}$, second order term of $\mathrm{A}$, second order term of $\mathrm{B}$ and combined First order term factor of $\mathrm{A}$ and second order term factor of B.After eliminating the non-significant terms the regression model is fairly fitted with the observed data, hence the final response model equation for the tensile stress is given in coded factor.

Tensile stress $=24.14-1.25 \times \mathrm{A}-2.5 \times \mathrm{B}-\mathrm{AB}+1.27 \mathrm{x}$ $\mathrm{A}^{\wedge} 2-0.98 \times \mathrm{B}^{\wedge} 2-1.25 \times \mathrm{AB}^{\wedge} 2$

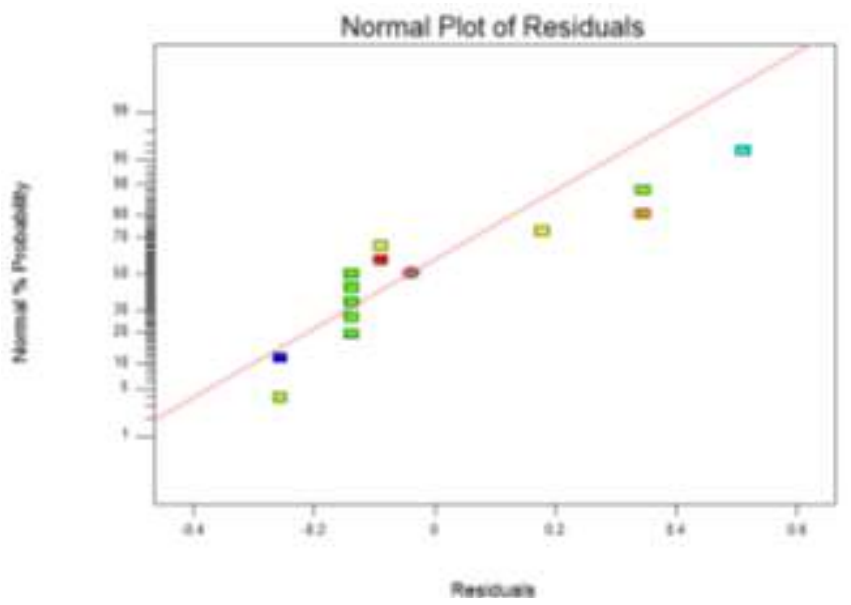

Fig. 1 Normal probability plot of residuals for tensile stress

Figure 1 shows that normal probability plot of residuals for the tensile stress. It gives the proportionality of the information about factors which influence with ANOVA results. It is noticed that the straight line formed by the results, indicated that the errors are distributed normally, which is the good sign of correlation.

Figure 2 clearly illustrated that the layer thickness range between 0.2 and $0.205 \mathrm{~mm}$ and the printing speed range between 30 and $32.5 \mathrm{~mm} / \mathrm{s}$, the tensile stress value lice greater than $28 \mathrm{MPa}$ as shown from the contour graph. Further, it is also indicated that while the printing speed between 33 and $44 \mathrm{~mm} / \mathrm{s}$ and the layer thickness 0.205 and 0.245 the tensile stress spears to reduce to $26 \mathrm{MPa}$.

Figure 3 illustrate the response surface elimination for the tensile stress with the individual parameters of the layer thickness and the printing speed. As the figure shows the tensile stress tends to decrease steadily with the increase in printing speed and slightly by the layer thickness. Since the printing speed will have more influence in the tensile stress with slight increase of layer thickness. From Table 6, model indicate that the percentage contribution for the factor $\mathrm{B}$ to a higher percentage of 52.8. It clearly shows that the layer thickness has been less significant on tensile stress when compared with the printing speed.

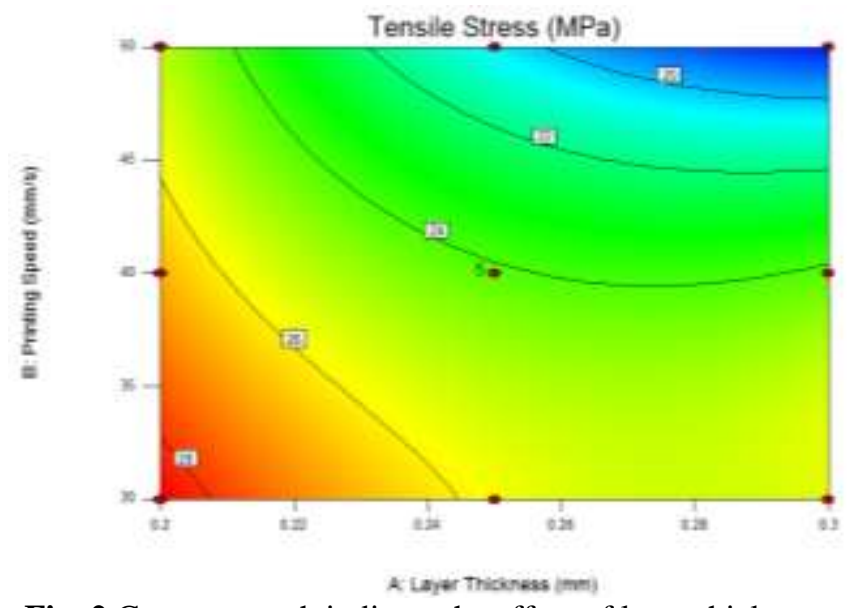

Fig. 2 Contour graph indicate the effect of layer thickness and printing speed on tensial stress

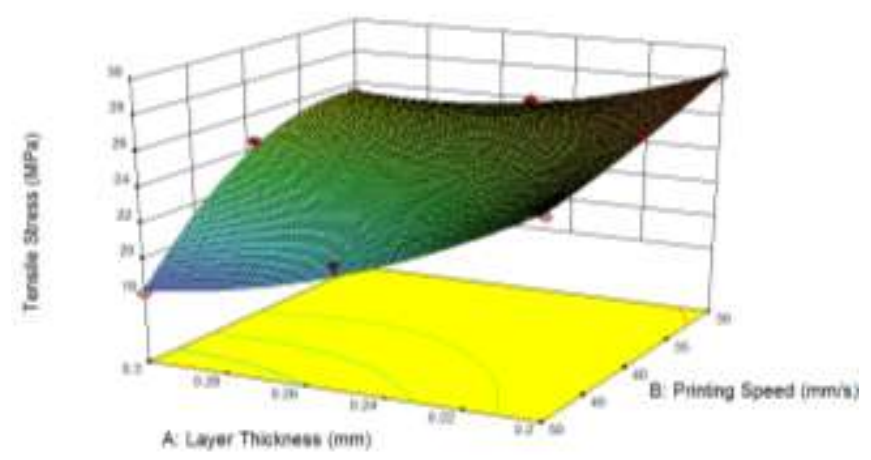

Fig. 3 Response surface graph indicate the effect of layer thickness and printing speed on tensial stress

From the results, it is clearly shown that the ABS + hydrous magnesium silicate composite material fabricated using 0.6 $\mathrm{mm}$ nozzle with $0.2 \mathrm{~mm}$ layer thickness and $30 \mathrm{~mm} / \mathrm{s}$ printing speed exhbited a maximum tensial strength of 28.5 MPaand the sample with $0.3 \mathrm{~mm}$ layer thickness and having printing speed of $50 \mathrm{~mm} / \mathrm{sshowed} \mathrm{a} \mathrm{lowest} \mathrm{tensile} \mathrm{stress} \mathrm{of}$ $17 \mathrm{MPa}$. The tensile strength of $0.3 \mathrm{~mm}$ layer thickness with a printing speed of $50 \mathrm{~mm} / \mathrm{svery}$ low, probably due to the additive manufacturing/ layered manufacturing samples have weak interlayer bonding or inter layer porosity [6]. The result further conforming that the layer orientation of additive manufacturing/ layered manufacturing samples contributes to the anisotropic properties [8]. Tensile testing causes low strength interference between 2D laminates or layer to delaminate prior to the fracture of 2D laminates or layers. Delamination is frequently observed in layered materials and the stress variation was due to the delamination [10].

\subsection{Flexural strength}

Table 3clearly shows the experimenta results results of flexural strength of $\mathrm{ABS}$ the $\mathrm{ABS}+$ hydrous magnesium silicate composite material fabricated using $0.6 \mathrm{~mm}$ nozzle with $0.2 \mathrm{~mm}$ layer thickness and $30 \mathrm{~mm} / \mathrm{s}$ printing speed exhibited a maximum flexural load of 48.59 MPaand the sample with $0.3 \mathrm{~mm}$ layer thickness and having printing speed of $50 \mathrm{~mm} / \mathrm{s}$ showed a lowest flexural load of 24.86 
MPa. The flexural load of $0.3 \mathrm{~mm}$ layer thickness with a printing speed of $50 \mathrm{~mm} / \mathrm{sexhibited} \mathrm{very} \mathrm{low} \mathrm{flexural} \mathrm{laods.}$ This is probably due to the additive manufacturing samples have weak interlayer bonding or inter layer porosity and also suggested by other reseachers [6]. The results further confirming that the layer orientation of additive manufacturing/ layered manufacturing samples contributes to the anisotropic properties [8]. Flexural testing which causes to the low strength interference between 2D laminates or layer to delaminate prior to the fracture of 2D laminates or layers. Delamination is frequently observed in layered materials, stress variation due to delamination [10].

Table:7 ANOVA -Response Surface Reduced Quartic model for Flexural strength without elimination

\begin{tabular}{lrrrrrl}
\hline Source & Sum of Squares & df & Mean Square & F Value & P-Value & Effect \\
\hline Model & 327.67 & 7 & 46.81 & 42.52 & 0.0004 & significant \\
A-Layer Thickness & 22.98 & 1 & 22.98 & 20.88 & 0.0060 & significant \\
B-Printing Speed & 10.22 & 1 & 10.22 & 9.28 & 0.0285 & significant \\
AB & 0.000 & 1 & 0.000 & 0.000 & 1.0000 & In-significant \\
$\mathrm{A}^{\wedge} 2$ & 11.34 & 1 & 11.34 & 10.30 & 0.0237 & significant \\
$\mathrm{B}^{\wedge} 2$ & 0.15 & 1 & 0.15 & 0.14 & 0.7263 & In-significant \\
$\mathrm{A}^{\wedge} 2 \mathrm{~B}$ & 20.86 & 1 & 20.86 & 18.95 & 0.0073 & significant \\
$\mathrm{AB}^{\wedge} 2$ & 6.81 & 1 & 6.81 & 6.19 & 0.0553 & In-significant \\
$\mathrm{A}^{\wedge} 3$ & 0.000 & 0 & & & & \\
$\mathrm{~B}^{\wedge} 3$ & 0.000 & 0 & & & & \\
Residual & 5.50 & 5 & 1.10 & & & \\
Lack of Fit & 5.50 & 1 & 5.50 & & & \\
Pure Error & 0.000 & 4 & 0.000 & & & \\
Cor Total & 333.17 & 12 & & & & \\
\hline
\end{tabular}

$\mathrm{R}^{2}=0.9835$, adj $\mathrm{R}^{2}=0.9604$

The Table 7 provide the fit summary of the quadratic model was statistically significant for analysis of tensile stress. The results the quadratic model for Flexural strength in the form of ANOVA were given in the Table 7 . The $\mathrm{R}^{2}$ value was $98.35 \%$ and adj $\mathrm{R}^{2}$ was $96.04 \%$. This clearly indicates the regression graph provides an admirable description to the correlation between the flexural strength and the independent factors. The p-value of the model is lower than 0.05 or $95 \%$ confidence indicated that the model is considered as statistically significant. From the ANOVA technique, it is calculated that the value of $\mathrm{F}$ ratio of the proposed model doesn't exceeded the standard value. The effect of the factor for $F$ value is high that indicate that facture is more influence the response process.

Coded factor equation

$\begin{array}{ll}\text { Flexural } & 35.42-3.39 \times \mathrm{A}-2.26 \times \mathrm{B} \\ \text { Strength }= & +8.724 \mathrm{e}^{-15} \times \mathrm{AB}+2.03 \times \mathrm{A}^{\wedge} 2- \\ & 0.23 \times \mathrm{B}^{\wedge} 2-3.96 \times \mathrm{A}^{\wedge} 2 \mathrm{~B}-2.26 \times \\ & \mathrm{AB}^{\wedge} 2\end{array}$

The transformed value of the coded factors (A and B) with the actual factors, hence the Eq. 5 can be written as:

Flexural $\quad 35.42-3.39 \times$ Layer Thickness -

Strength $=\quad 2.26 \mathrm{x}$ Printing Speed $+8.724 \mathrm{e}^{-15} \mathrm{x}$

Layer Thickness $x$ Printing Speed

+2.03 x Layer Thickness $\wedge 2-0.23$

$\mathrm{x}$ Printing Speed ^2 -3.96 x Layer

Thickness $\wedge 2 \mathrm{x}$ Printing Speed -

$2.26 \times$ Layer Thickness $x$ Printing

Speed ${ }^{\wedge} 2$

Table:8 ANOVA -Response Surface Reduced Quartic model for flexural strength after elimination

\begin{tabular}{|c|c|c|c|c|c|c|c|}
\hline Source & Sum of Squares & df & Mean Square & F Value & P-Value Prob > F & Effect & $\%$ contribution \\
\hline Model & 320.71 & 4 & 80.18 & 51.46 & $<0.0001$ & significant & 96.26 \\
\hline A-Layer Thickness & 143.86 & 1 & 143.86 & 92.33 & $<0.0001$ & significant & 43.1 \\
\hline B-Printing Speed & 10.22 & 1 & 10.22 & 6.56 & 0.0336 & significant & 3.06 \\
\hline $\mathrm{A}^{\wedge} 2$ & 12.12 & 1 & 12.12 & 7.78 & 0.0236 & significant & 3.63 \\
\hline $\mathrm{A}^{\wedge} 2 \mathrm{~B}$ & 20.86 & 1 & 20.86 & 13.39 & 0.0064 & significant & 6.26 \\
\hline Residual & 12.46 & 8 & 1.56 & & & & \\
\hline Lack of Fit & 12.46 & 4 & 3.12 & & & & \\
\hline Pure Error & 0.000 & 4 & 0.000 & & & & \\
\hline Cor Total & 333.17 & 12 & & & & & \\
\hline
\end{tabular}

$\mathrm{R}^{2}=0.9626$, adj. $\mathrm{R}^{2}=0.9359$ 
Table 8 shows the ANOVA table of quadratic model after the backward elimination. The result of the reduced model shows that the model is significant with a $\mathrm{R}^{2}$ value as $963.26 \%$ and the adjutant $R^{2}$ value as $93.59 \%$. The effect of the significant $\mathrm{F}$ values and the factor $\mathrm{A}$ is Layer thickness, factor B Printing speed, combination first order term factor of $\mathrm{AB}$, second order term of $\mathrm{A}$, second order term of $\mathrm{B}$ and combined First order term factor of $\mathrm{A}$ and second order term factor of B.After eliminating the non-significant terms the regression model is fairly fitted with the observed data, hence the final response model equation for the flexural strength is given in coded factor.

Flexural Strength $=35.35-4.9 \times \mathrm{A}-2.26 \times \mathrm{B}+1.94 \times \mathrm{A}^{\wedge} 2$ $-3.95 \times \mathrm{A}^{\wedge} 2 \mathrm{~B}$

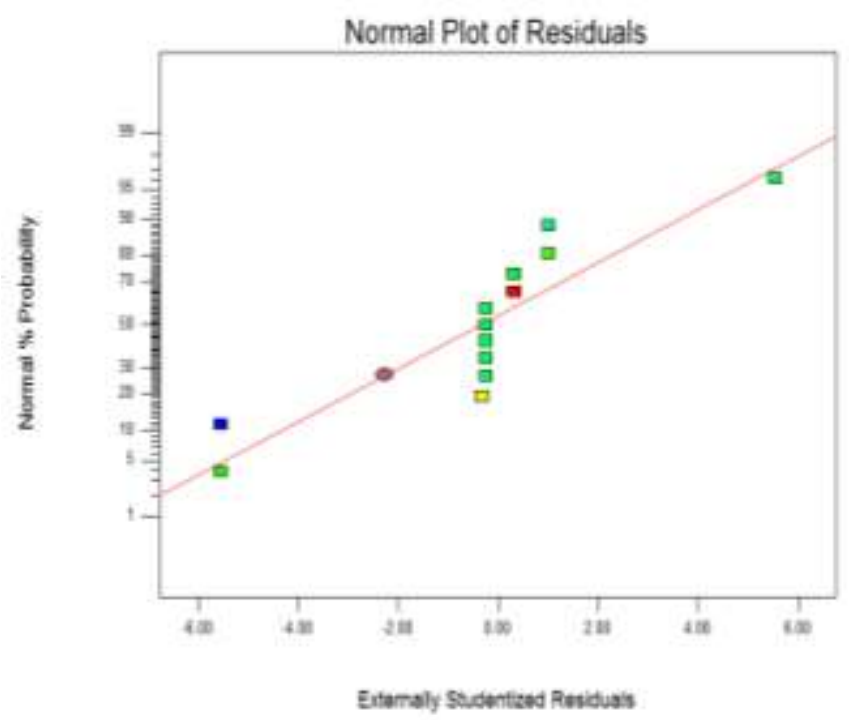

Fig. 4 Normal probability plot of residuals for flexural strength

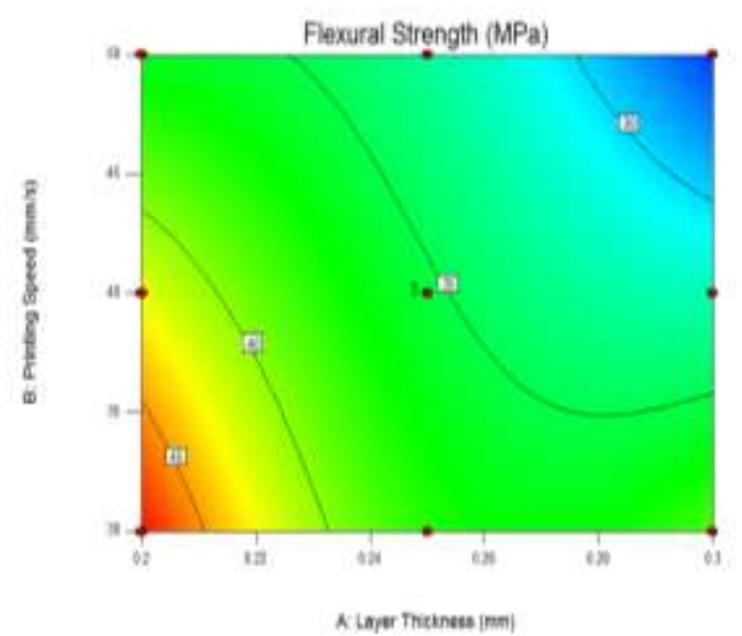

Fig. 5 Contour graph indicate the effect of layer thickness and printing speed on flexural stress

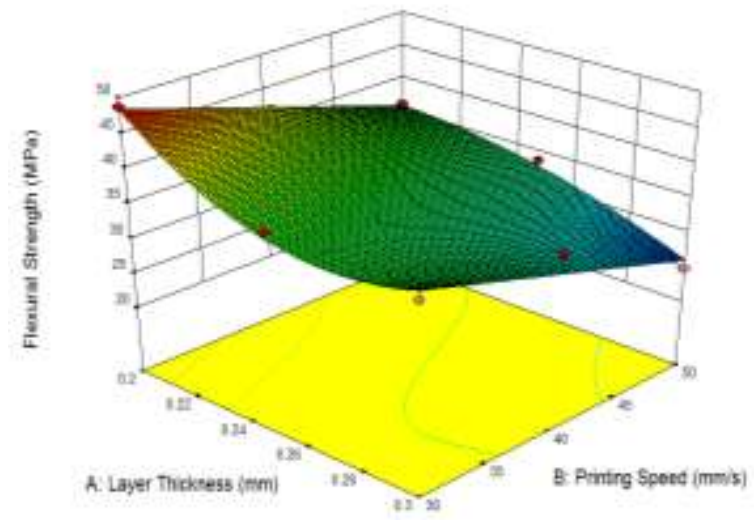

Fig. 6 Response surface graph indicate the effect of layer thickness and printing speed on flexural stress

Figure 4 shows that normal probability plot of residuals for the flexural strength. It gives the proportionality of the information about factors which influence with ANOVA results. It is noticed that the straight line formed by the results, indicated that the errors are distributed normally, which is the good sign of correlation.

When the layer thickness range between 0.2 and $0.21 \mathrm{~mm}$ and the printing speed range between 30 and $34 \mathrm{~mm} / \mathrm{s}$, the flexural strength value lice greater than $45 \mathrm{MPa}$ as shown from the contour graph (Fig. 5). Further, it is also indicated that while the printing speed between 34 and $41 \mathrm{~mm} / \mathrm{s}$ and the layer thickness 0.21 and 0.23 the flexural strength spears to reduce to $40 \mathrm{MPa}$.

Figure 6 illustrate the response surface elimination for the flexural strength with the individual parameters of the layer thickness and the printing speed. As the figure, shows the flexural strength tends to decrease steadily with the increase in layer thickness and slightly by the printing speed. Since the printing speed will have more influence in the tensile stress with slight increase of layer thickness. From Table 9, model indicate that the percentage contribution for the factor A to a higher percentage of 43.1. It clearly shows that the layer thickness has been significant on flexural strength when compared with the printing speed.

\section{CONCLUSIONS}

ABS + hydrous magnesium silicate composite material was successfully fabricated by using desktop 3D printer, based on the various manufacturing parameters. With a help an empirical model analysis of manufacturing parameter influence on tensile and flexural in PLA led to the following conclusions:

1. A maximum tensile and flexural strength values are reported for samples whichhas low layer thickness of $0.2 \mathrm{~mm}$ andprinting speed of $30 \mathrm{~mm} / \mathrm{s}$.

2. The tensile stress increases steadily with decrease in printing speed and slightly by an increase in the layer thickness. 
3. The Flexural strengthwas increased consistently with decrease in the layer thickness and slightly increasedby the printing speed.

4. The mathematical models were developed to predict the tensile stress and flexural strength parameter subject to manufacturing process parameters.

\section{REFERENCES}

[1] Standard Terminology for Additive Manufacturing Technologies. ASTM International Designation : F2792-12a (2012)

[2] Stucker B “Additive Manufacturing Technologies: Technology introduction and business implications. In: Frontiers of engineering; report on leading - edge engineering" from 2011 symposium. National academies press, WashingtonDC: 5-14(2012).

[3] M.L. Shofner, K. Lozano, F.J. Rodr1'guez-Mac1'as, E.V. Barrera, Nanofiber-reinforced polymers prepared by fused deposition modeling. J. Appl. Polymer. Sci. 89(11): 3081-3090 (2003).

[4] M.L. Shofner, F.J. Rodri'guez-Mac1'as, R. Vaidyanathan, E.V. Barrera, Single wall nanotube and vapor grown carbon fiber reinforced polymers processed by extrusion freeform fabrication. Composites 34(12), 1207-1217 (2003).

[5] Vishu shah: Handbook of Plastic Testing Technology second Edition, New York (1998).

[6] Es Said, Os Foyos J, Noorani R, Mandelson M, Marloth R, Pregger BA. Effect of layer orientation on mechanical properties of rapid prototyped samples. Mater Manuf. Process, 15(1):107-122, (2000).

[7] Russell A.Giordano, Benjamin M.Wu, Scorr W. Borland, Linda G.Cima, Emanuel M.. Sachs, MichaelJ.Cima, Mechanical properties of dense polylatic acid structures fabricated by three dimensional printing, Journal of Biomaterials Science, Polymer Edition, 8(1) :63-75, (1996).

[8] Ahn SH, Montero M, Odell D, Roundy S, Wright PK. Anisotropic material properties of fused deposition modelling ABS. Rapid Prototyping J,8(4):248-57, (2002).

[9] Khan ZA, Lee BH, Abdullah J. Optimization of rapid prototyping parameters for production of flexible ABS object. J Mater Process Technology, 169:54-61, (2005).

[10] Lee CS, Kim SG, Kim HJ, Ahn SH. Measurement of anisotropic compressive strength of rapid prototyping parts. J Mater Process Technology, 630(7) :187- 188, (2007).

[11] Jaya Christiyan K G, U. Chandrasekhar, K. Venkateswarlu, "Influence of raster orientation and layer thickness on mechanical properties of ABS material using FDM process", IJARSE, Vol. No.3, Special Issue (01), September:1-6, (2014).

[12] Myers RH, Montgomery DC (2002) Response surface methodology, Wiley. 